\title{
Nyam, T.T.
}

\section{Use of Sugarcane Rind Activated Carbon For Removal Of Organic Content In Wastewater.}

\author{
n.tobias@kadunapolytechnic.edu.ng \\ Department of Chemical Engineering, \\ Federal Polytechnic, Kaduna, Nigeria.
}

This article is covered and protected by copyright law and all rights reserved exclusively by the Centre for Petroleum, Pollution Control and Corrosion Studies.

(CEFPACS) Consulting Limited.

Electronic copies available to authorised users.

The link to this publication is https://ajoeer.org.ng/otn/ajoeer/qtr-2/2020/04.pdf 


\title{
USE OF SUGARCANE RIND ACTIVATED CARBON FOR REMOVAL OF ORGANIC CONTENT IN WASTEWATER.
}

\author{
${ }^{1}$ Nyam, T.T.; ${ }^{1}$ Nwosibe, P.O.; ${ }^{2}$ Atiwurcha, N. I and ${ }^{1}$ Okechukwu, J. O \\ ${ }^{1}$ Chemical Engineering Department Federal Polytechnic, Kaduna, Nigeria \\ ${ }^{2}$ Petroleum Engineering Department, University of Aberdeen, UK
}

n.tobias@kadunapolytechnic.edu.ng

\begin{abstract}
:
In this study, activated carbon produced from sugarcane rind was used to treat synthesized wastewater for the removal of formaldehyde. The prepared precursor was impregnated with $\mathrm{ZnCl}_{2}$ before carbonization at $300^{\circ} \mathrm{C}$ for 30 minutes. Proximate analysis of the produced activated carbon showed that it had a moisture content of $15.3 \%$, ash content of $5 \%$, and fixed carbon of $69.7 \%$ amongst others. While BET analysis revealed the activated carbon has a surface area of $328.87 \mathrm{~m}^{2}$ and a pore diameter of $2.840 \mathrm{e}+00 \mathrm{~nm}$. When used in batch process treatment of wastewater the activated carbon showed an $18-25 \%$ adsorption efficiency in removal of formaldehyde from the wastewater. This shows that this sugarcane rind hitherto considered as waste and a pollutant has values to be explored.
\end{abstract}

Keywords: Activated carbon, Formaldehyde, organic content, wastewater, Sugarcane peels, Sugarcane Rind etc.

\subsection{INTRODUCTION}

Wastewaters (WW) are laden with hazardous and toxic pollutants that come in the form of spent catalysts, acids, hydrocarbons and soluble bases; the constituent WW varies from place to place (Ali, 2012). Wastewater is a concern hence there have been efforts to find means of bringing the pollutants to acceptable levels before discharge into waterways which often times are rivers, (Kigho, Smith, \& Evuensiri, 2016; Nwafulugo, 2014; Ali, 2012).

Barakat, (2011), Awaleh \& Soubaneh, (2014), Diya'uddeen, Daud, \& Abdul Aziz, (2011) chronicled methods that have been utilized in the treatment of WW. Adsorption features prominently as a technique, studies have been refocusing on low-cost absorbents (Kigho, et al., 2016; Sunil, 2014) and agricultural waste has been receiving the most attention in this regards. 
The global production of sugarcane is put at 179.9 million tons in 2019 (USDA, 2019). In Nigeria, estimated production is about 80,000 tons of sugarcane within 2019 (Knoema, 2019) most of the commercial component of Nigeria's sugarcane comes from states like; Kastina, Taraba, Kano, Adamawa, Jigawa, Kaduna, Kebbi, and Sokoto State. There is, of course, a capacity to increase the production sugarcane in states like Nassarawa, Benue, Kwara, and Niger.

The quantum of sugarcane produced in the absence of industrial processing is consumed by peeling off the rind, chewing the pith to smoke the liquid released from the chewing. Saleh and Maigandi, (2014) estimated an average of $1040.36 \mathrm{~kg} /$ day of sugarcane rind produced from 1118.67 stems of sugarcane per day across some peeling centers in Nassarawa Local Government Area in Kano State. This vast quantity of rind produced across Nigeria served at that time no purpose but nuisance which was burnt. Subsequent studies have explored the possibility of using the rind as feed component for animals (Saleh \& Ayoade, 2018; Mohammed \& Saleh, 2018).

Literature is brimming with studies that use Sugarcane bagasse - a mix of pith and rind, raffinate from sugar production process - in the production of activated carbon; sugar cane rind mostly considered a waste and good enough for fire and litter in the environment is only beginning to receive attention as a precursor for activated carbon, This paper thus, seeks to establish the appropriateness or otherwise for the use Sugarcane Rind Activated Carbon (SCRAC) in the treatment of water laden with organic component namely formaldehyde.

\subsection{MATERIALS AND METHODS}

Sugarcane rind was collected from the peeling center in Kaduna, it was cleaned and impregnated with an already prepared activation agent $-\mathrm{ZnCl}_{2}$ in ratio 1:5. The impregnated rind was oven-dried at $120{ }^{\circ} \mathrm{C}$ for 2 hours. The impregnated rind was charred and then 
carbonized at a Temperature of $300{ }^{\circ} \mathrm{C}$ for 30 minutes in a muffle furnace, after which it was cooled and stored away until when needed. The SCRAC was washed in water until a nearneutral $\mathrm{pH}$ was attained again it was dried and stored away in an appropriate container.

\subsection{Characterisation}

The morphology and elemental composition of the SCRAC were determined using SEMEDS; the functional group was determined by FT-IR (Shimadzu, Japan) while the contour description was determined by BET analysis. The proximate analysis was done using methods described by Ekpete et al., (2017).

\subsection{Wastewater Treatment}

Wastewater containing formaldehyde was synthesized for batch process treatment in order to remove formaldehyde. Three grams of adsorbent was mixed with $50 \mathrm{ml}$ of formalin solution in a beaker, the mix was kept in a state of agitation for 30 minutes using a magnetic stirrer at a temperature ranging between $27{ }^{\circ} \mathrm{C}$ to $37{ }^{\circ} \mathrm{C}$ after which it was filtered. The process was repeated for $60,90,120$, and 150 minutes to determine the effect of time on the efficiency of the produced adsorbent. The filtrate was analyzed using a UV spectrophotometer (Shimadzu, Japan) at a wavelength of $264 \mathrm{~nm}$. The equilibrium adsorption capacity $\left(\mathrm{q}_{\mathrm{e}}\right)$ of the adsorbent (activated carbon) was calculated using the following equation:

$\mathrm{q}=\frac{C_{0}-C_{e}}{m} x V$

Where

$\mathrm{qe}=$ the adsorption capacity of formaldehyde $(\mathrm{mg} / \mathrm{g})$,

$\mathrm{C}_{\mathrm{o}}$ and $\mathrm{C}_{\mathrm{e}}=$ initial and filtrate concentrations in the solution $(\mathrm{mg} / \mathrm{L})$, respectively.

$\mathrm{V}=$ is the formalin solution volume ( $\mathrm{ml}$ or $\mathrm{L})$ and 
$\mathrm{M}=$ is the mass of adsorbent $(\mathrm{g})$.

Formaldehyde adsorption efficiency is the ratio of the difference between initial and filtrate concentration divided by the initial concentration multiplied by 100 is expressed as:

$\% \mathrm{RE}=\frac{C_{0}-C_{e}}{C_{0}} \times 100$

\subsection{RESULTS AND DISCUSSION}

\subsection{Proximate Analysis}

The results of the proximate analysis is thus:

Table 1 Proximate analysis of the activated carbon produced.

\section{PARAMETERS RESULTS}

Moisture content \% 15.3

Ash content \% $\quad 5.0$

Volatile matter \% 10

Fixed carbon \% 69.7

pH 7.2

Bulk density \% $\quad 5.45$

\subsubsection{Moisture Content}

The results in Table 1 depict the physical properties of the produced activated carbon, which has a moisture content of $15.3 \%$, this is approximately at the maximum of some reported National Industrial Standards which is 15\% (Maulina \& Iriansyah, 2017; Ariany, Ghina, \& Amelia, 2017). Activated carbon absorbs water from the atmosphere owing to its hygroscopic nature when not handled effectively (cooling and packing) to curtail this phenomenon. The rate of absorption of water is increased by the activity or concentration of activating agent 
which increase the pore volume and surface area (Maulina \& Iriansyah, 2017). Increased carbonization temperature and time can bring about activated carbon with less moisture content hence a product with better adsorptive capacity.

\subsubsection{Ash Content}

The ash content of the SCRAC in this study is $5.0 \%$, a value which is average compared with National Standards reported by other workers as stated above. High ash content has the tendency of plummeting the mechanical strength of activated carbon hence its adsorptive capability (Ariany, Ghina, \& Amelia, 2017). Ekpete et al., (2017) add that not only does ash content affect adsorption capacity of activated carbon it also affects the reactivation efficiency by reducing it, but they also conclude by submitting that activated carbon with lower ash content can make better adsorbents.

\subsubsection{Volatile Matter}

The volatile matter in the SCRAC is $10 \%$, again at an average level. The activating agent, as well as carbonization temperature, have an effect on how much volatile matter that can be traceable in the final product. The combination of the activities of both agencies witnesses the liberation of non-carbon elements such as oxygen, hydrogen, nitrogen, while others such as compounds of silica become prominent (Maulina \& Iriansyah, 2017).

\subsubsection{Fixed Carbon}

Fixed carbon in the final product is $69.7 \%$, this value is a function of the type of precursor i.e. it's content in convertible carbon of its cellulose, lignin, and pyrolysis, (Maulina \& Iriansyah, 2017) The value obtained from the precursor used shows the precursor is a good material to use. 


\section{$3.1 .5 \mathrm{pH}$}

The $\mathrm{pH}$ of the SCRAC produced is 7.2 this value agrees with the report by Ariany et al., (2017) which shows that sugarcane bagasse activated carbon have $\mathrm{pH}$ in the alkaline range. It must be noted that the $\mathrm{pH}$ reported here was after series of washing in water

\subsection{Morphology and Elemental Composition}

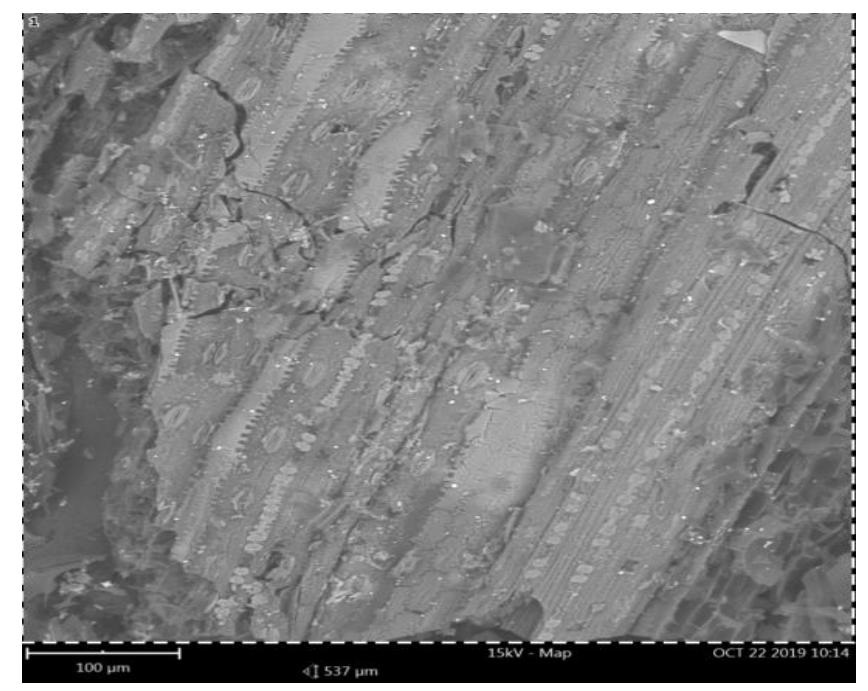

Figure 1: SEM image of Sugarcane Activated Carbon

Figure 1 shows the morphology of the SCRAC under a Scanning Electron Microscopy (SEM),

Table 2: EDS Result showing Elemental Composition of SCRAC

\section{Element Weight Conc.}

$\begin{array}{lc}\mathrm{C} & 57.79 \\ \mathrm{Si} & 17.55 \\ \mathrm{~K} & 10.57 \\ \mathrm{O} & 9.94 \\ \mathrm{Cl} & 0.89 \\ \mathrm{~N} & 0.78\end{array}$




$\begin{array}{cc}\mathrm{Ca} & 0.67 \\ \mathrm{Al} & 0.57 \\ \mathrm{P} & 0.52 \\ \mathrm{Mg} & 0.40 \\ \mathrm{~S} & 0.24 \\ \mathrm{Na} & 0.08\end{array}$

The results in Table 2 show carbon dominate capacity, the large quantity of Silicon may not be unconnected with the crucible type used during carbonization, it clay. Though it is also a pointer to observations that carbonization of agricultural waste witnesses the volatilization of some components silica concentration tends to increase.

Table 3: BET Result of SCRAC

\begin{tabular}{ll}
\hline Parameters & Results \\
\hline BET surface area $\left(\mathbf{m}^{2} / \mathbf{g}\right)$ & 328.870 \\
Micropore surface $\mathbf{a r e a}\left(\mathbf{m}^{2} / \mathbf{g}\right)$ & 377.667 \\
Micropore volume $(\mathbf{c c} / \mathbf{g})$ & 0.134 \\
Adsorption energy $(\mathbf{K j} / \mathbf{m o l})$ & 4.453 \\
Pore Diameter $(\mathbf{n m})$ & $2.840 \mathrm{e}+00$ \\
Pore size $(\mathbf{n m})$ & $5.839 \mathrm{e}+00$
\end{tabular}

The BET results in Table 3 show the SCRAC pore volume of $0.134 \mathrm{~cm}^{3} \mathrm{~g}-1$ a marked improvement over that of the precursor which was $0.0467 \mathrm{~cm}^{3} \mathrm{~g}-1$. The pore diameter $(2.840 \mathrm{e}+00 \mathrm{~nm})$ also serves as a guide as to what solvent can be adsorbed on the SCRAC.

3.4 Functional Group 


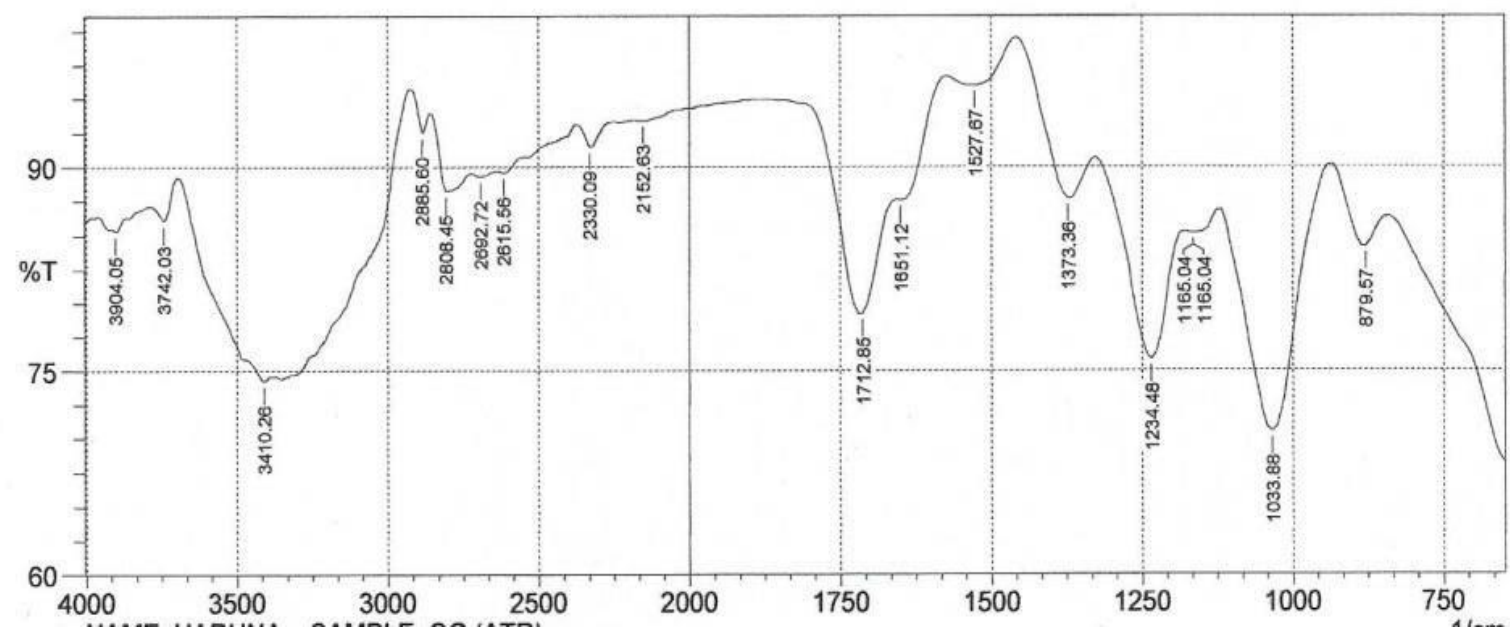

Figure 2: FT-IR analysis of CSRAC

The FT-IR spectra were recorded to characterize the functional groups that are available on the CSRAC surface which is shown in Fig. 2 ranging from 879.57 to 3904.05 peaks. Typical of agricultural commodities which are made of cellulose, hemicellulose, and lignin. Fig. 2 reveals the existence of the $\mathrm{O}-\mathrm{H}$ functional group, the presence of nitrogen compounds in the structure is confirmed by N-H asymmetric stretch peak at particularly 3410 (3500-3200) cm-1 which are vibrations for alcohol and amide respectively. The band between 1020 and 1275 has attributes of $\mathrm{C}-\mathrm{N}$ and $\mathrm{C}-\mathrm{O}$ stretching amine and alkyl aryl ether. Moreover, the band wave number of around $1560 \mathrm{~cm}^{-1}$ proves that the porous carbon contains the $\mathrm{C}-\mathrm{C}$ stretching aromatic ring, which helps in determining the main functional group in SCRAC as amine and alcohol. The functional group alongside pore diameter is critical in the determination of what contaminant to be eradicated from wastewater. 


\subsection{Adsorption Test}

Table 4 Results of Synthesised Wastewater Treatment with SCRAC

\begin{tabular}{ccccc}
\hline $\begin{array}{c}\text { Duration } \\
\text { (minutes) }\end{array}$ & $\begin{array}{c}\text { Initial concentration } \\
\mathrm{C}_{\mathrm{o}} \\
(\mathrm{mg} / \mathrm{L})\end{array}$ & $\begin{array}{c}\text { Final concentration } \\
\mathrm{C}_{\mathrm{c}} \\
(\mathrm{mg} / \mathrm{L})\end{array}$ & $\begin{array}{c}\text { Adsorption } \\
\text { Capacity } \\
\left(\mathrm{q}_{\mathrm{c}}\right)\end{array}$ & $\begin{array}{c}\text { Adsorption } \\
\text { Efficiency } \\
(\%)\end{array}$ \\
\hline 30 & 0.804 & 0.6513 & 2.545 & 18.99 \\
60 & 0.804 & 0.6243 & 2.995 & 22.35 \\
90 & 0.804 & 0.6107 & 3.222 & 24.04 \\
120 & 0.804 & 0.604 & 3.333 & 24.88 \\
150 & 0.804 & 0.5967 & 3.455 & 25.78 \\
\hline
\end{tabular}

From the results in Table 4, it is evident, within the limits of the study, that with an increased retention time of adsorbent held in the wastewater the SCRAC's adsorption efficiency increases; though the rate is less than $50 \%$. The low adsorption may not be unconnected with the adsorbent's high moisture content as earlier seen. It can however, serve as a primary adsorbent for reduction of organic content load especially if it shows the capacity to adsorb phenol, etc.

\subsection{CONCLUSION}

From the results of the study, it can be concluded that: -

- Sugarcane Rind is a precursor that can be used in the production of low cost activated carbon whose yield is over $50 \%$ activated carbon and 675 fixed carbon. The product had low ash content great pore volume as revealed by Bruner-Emmett-Teller (BET) among other factors; this impact upon waste valorization of the precursor;

- The synthesized sugarcane rind activated carbon had an adsorption efficiency of 18.99 $-25.78 \%$ removal of formaldehyde from synthesized wastewater at different retention times; the major limitation to its use remains the lack of detailed research on how to improve the performance of the activated carbon. 


\subsection{RECOMMENDATIONS}

The following recommendations can help in fine-tuning the use of sugarcane rind as a precursor for activated carbon production:

- A holistic adsorption isotherm study needs to be conducted on the SCRAC to effectively characterize it.

\subsection{ACKNOWLEDGEMENT}

While declaring that there is no area of conflict, the authors wish to acknowledge in no small measure the roles of Akegah Daniel, Yunusa Idris, Aliyu Usman who at various stages of this study provided insight to content.

\section{References}

Ali, H. A. (2012). Removal of Heavy Metals from Industrial Wastewater Petroleum Refinery. retrieved 19/4/2017 from http://www.uotechnology.edu.iq/dep-chemeng/THESIS/HDepl_1/ali_h.pdf: Thesis submitted to University f Technology.

Ariany, Z., Ghina, H. F., \& Amelia, S. R. (2017). The potential of activated carbon derived from the bio-char waste of bio-oil pyrolysis as adsorbent. ICET4SD 2017 (p. 154). MATEC Web of Conferences, 01029 (2018) Available on https://doi.org/10.1051/matecconf/201815401029.

Awaleh, M., \& Soubaneh, Y. (2014). Wastewater Treatment in Chemical Industries: The Concept and Current Technologies. Hydro Current.

Awaleh, M., \& Soubaneh, Y. (2014). Wastewater Treatment in Chemical Industries: The Concept and Current Technologies. Hydro-current, .

Barakat, M. (2011). New Trends in Removing Heavy Metals from Industrial Wastewater. Arabian Journal of Chemistry, 361-377.

Diya'uddeen, B. H., \& Abdul Aziz, A. (2011). Treatment Technologies for Petroleum Refinery Effluents: A Review. . Process Safety and Environmental Protection, 95-105.

Ekpete, O., Marcus, A., \& Osi, V. (2017). Preparation and Characterization of Activated Carbon Obtained from Plantain (Musa paradisiaca) Fruit Stem. Hindawi Journal of Chemistry, Available on https://doi.org/10.1155/2017/8635615.

Kigbo, M., Smith, O., \& Evuensiri, O. (2016). Application of Cassava Peels Activated Carbon in the Treatment of Oil Refinery Wastewater - A Comparative Analysis. Journal of Ecological Engineering, 52-58. 
Knoema. (2019). Knoema. Retrieved from Nigeria - Sugar Production Quantity: https://knoema.com/atlas/Nigeria/topics/Agriculture/Crops-Production-Quantitytonnes/Sugar-cane-production

Maulina, S., \& Iriansyah, M. (2017). Characteristics of activated carbon resulted from the pyrolysis of the oil palm fronds powder. IOP Conf. Series: Materials Science and Engineering 309 (2018) 012072 (p. 309). Available on doi:10.1088/1757-899X/309/1/012072: IOP Publishing.

Mohammed, Y., \& Saleh, G. (2018). Effect of Feeding Sugarcane (S. officinarum) Peels Meal Based Diets on Haematological Profile and Serum Biochemistry of Fattening Yankasa Sheep.

International Journal of Innovative Biochemistry \& Microbiology Research, 6(2):9-15, 9-15.

Nwafulugo, F. (2014). Application of Zeolite 4A-Metakaolin Matrix for the Removal of Some Heavy Metals from Crude Oil Tank farm Wastewater. retrieved 09/03/2016 from http://kubanni.abu.edu.ng:8080/jspui/: Thesis submitted to Ahmadu Bello University, Zaria.

Saleh, G., \& Ayoade, J. (2018). UTILIZATION OF COMPLETE DIET CONTAINING SUGARCANE. Animal Science Vol LXI No. I.

Saleh, G., \& Maigandi, S. A. (March 16th - 19th 2014). Quantification and Uses of Sugarcane Peels among the Sheep and Goats' owners in Nassarawa LGA Kano State. 39th Annual Conference of the Nigerian Society for Animal Production, (pp. 151-153). BABCOCK University, Ilishan_Remo, Ogun State.

Sunil, J. (2014). Preparation of Low-Cost Adsorbents: A Review. International Journal of Research, 1689-1692.

USDA. (2019, November). Foreign Agricultural Service Sugar: World Markets and Trade. Retrieved from https://apps.fas.usda.gov/psdonline/circulars/sugar.pdf

P. 674. 